\title{
Issues with Senior Workers in Hong Kong Construction Industry: Preliminary Observations and Intervention Opportunities
}

\author{
Tas Yong Koh", Steve Rowlinson', Stephen Pollock² \\ ${ }^{1}$ Department of Real Estate and Construction, University of Hong Kong, 501, 5/F Knowles Building, Pokfulam Road, Hong Kong \\ ${ }^{2}$ Leighton Contractors Asia, Unit D 12/F Menarco Tower Bonifacio Global City, 1634 Taguig City 32nd St, Phillipines \\ * Corresponding author, e-mail: tasykoh@hku.hk
}

Received: 15 January 2020, Accepted: 20 March 2020, Published online: 19 May 2020

\begin{abstract}
There is an increasingly larger proportion of workforce 50 years of age or older. This ageing trend is prevalent in the Hong Kong construction industry. The implications of this ageing trend for the construction industry are the decline in workforce productivity due to old age, compromised health, safety, and well-being; and the shortage of workforce. Coupled with various organisational and institutional shortcomings in the industry that lead to unfavourable working environment, these situations not only negatively affect the economic viability of the construction industry but also give rise to other psychosocial problems experienced by the older workers. Despite these situations, we know very little of the conditions older construction workers experience in the construction industry. There is therefore a need to investigate such issues and propose possible interventions to improve the working conditions of the senior workers. With these objectives, in this paper, we first report the findings of a small scale survey on the care of older workers in Hong Kong construction industry, and second propose potential intervention by combining the findings of the survey and our industry observations of the practices implemented by progressive contracting firms in Hong Kong. The findings reveal that despite the industry under appreciation of the ageing workforce, there are interventions implemented by progressive contracting firms that can potentially provide health and safety protection to the workforce of all ages although these firms are small in number. This article is an extended version of a conference paper that appeared as Koh et al. (2019).
\end{abstract}

\section{Keywords}

ageing workforce, construction workers, health safety and well-being, integrated approach, protection, promotion, working conditions

\section{Introduction}

The workforce in the 21st century is ageing. There is increasingly larger proportion of workforce 50 years of age or older. A few societal and demographic trends have led to this development (Loeppke et al., 2013) including general population ageing, increase life expectancy, and decline in fertility rates (Cheng et al., 2013; Loeppke et al., 2013). Hong Kong is not immune from these trends. These trends affect the composition and the supply of workforce. The most obvious result of these situations is the large increase of older workers. This situation brings about implication on workforce productivity and by extension, the economic prosperity of business enterprises. As physical and cognitive functions decline with age (Silverstein, 2008; Varianou-Mikellidou et al., 2019), the older workers' productivity suffers and susceptibility to ill-health and safety issues increase. It has been reported that due to the decline in cardio-vascular, pulmonary, and musculoskeletal functions and the ardous working conditions in construction, older workers have to work at much greater percentage of their capacity (Kenny et al., 2016) which lead to increased fatigue (López et al., 2018). Together with the decline in sensory systems (including hearing, vision, and balancing) (Varianou-Mikellidou et al., 2019), these physical impairments render the older workers at increased risk of safety incidents/accidents.

To remain competitive or to simply keep the business in operation, employers face the challenging tasks of having to maximise the contributions of both the old and young workers while at the same time addressing the health, safety, and well-being issues of the workforce (Loeppke et al., 2013). These ageing situations are prevalent in the Hong Kong construction industry considering the fact that about $41 \%$ of the total registered construction workers in Hong Kong are 
50-year-old or above [as at 31 August 2018 (CIC, 2019)], and the failure of the industry to attract younger workers, which have together led to serious manpower shortage (CIC, 2016; Sito, 2014; Tin et al., 2016).

As with most countries and regions, construction workers in Hong Kong experience physically demanding works on a daily basis. Workers are also subjected to constant psychosocial pressures including the need to face stressful environmental conditions, long and sometimes irregular work hours, unpredictable workplaces and conditions, and dis-continual employment (Schwatka et al., 2012). In addition, the organisational and institutional arrangements in Hong Kong construction industry are less supportive in providing favourable working environment for older workers (Leaviss et al., 2008). These less than desirable arrangements include having to be "self-employed" and finding work through subcontractors as daily rated workers the labour of which are not paid if workers are unable to work due to illness, reliance on piece-rate payment system which are not conducive for older workers with reduced productivity (let alone the negative impacts on workers pushing to complete the amount of "piece works" agreed at the expense of their own health and safety), and main contractors indifferent and minimalist attitude towards providing for the needs of older workers for fear of incurring additional costs in the highly competitive industry. These situations have given rise to a general disregard of ageing workforce issue in the Hong Kong construction industry although some quarters in the industry recognise the need to address such issues.

These conditions have collectively taken a toll on the safety, health, and well-being of construction workforce in general and older workers in particular. Despite these misgivings, we know very little of the conditions older construction workers experience in Hong Kong construction industry. There is therefore a need to investigate such issues and propose possible intervention to improve the working conditions of our senior workers. For these purposes, in this paper, we first report the findings of a small scale survey on the care of older workers in Hong Kong construction industry and second, propose potential intervention by combining the findings of the survey and our industry observations of the practices implemented by progressive contracting companies in Hong Kong.

\subsection{Hong Kong construction general workforce health, safety, and well-being}

Some works and research studies conducted in the past several years in Hong Kong construction industry have led to the revelation of insights on the general workforce health, safety, and well-being although these studies were not solely targeted at older workers. Notable among these studies were the four waves of health promotion and medical examination exercises conducted during the years 2013 to 2018 by staff members of two local universities - Rowlinson et al. (2014), Tin et al. (2016), Yi and Chan (2016), and the currently ongoing Chan's (2018) construction workers' health profiling project (Chan, 2018). In addition, the findings of a smallscale single-organisation construction workforce health survey have also been reported in a Hong Kong consrtuction industry event (Small, 2018). The results of these studies are summarised in Table 1.

In Table 1, the figures given in parentheses in the left column are the percentages of equivalent conditions sustained by the general population in Hong Kong (Chan and Ching, 2017). Comparison on selected health conditions can hence be made between the construction workforce and the general public. From Table 1, it can be seen that the studies converge to indicate that the local workforce sustain poor health conditions. There is a high prevalence of poor chronic health (e.g., hypertension and abnormal blood sugar levels) and undesirable life-style conditions (e.g., high-risk smoking and drinking) and long working hours. These long working hours lead to fatigue, less satisfaction in work-life balance, and compromised safety performance.

The senior workers do not fare much better as reported in Small (2018). The findings in this study indicate that among all the workers that sustained abnormal blood pressure, around $60 \%$ of the workers aged 51 or above; for workers with abnormal blood sugar level, over $55 \%$ aged 51 or above;

Table 1 Hong Kong workforce health conditions

\begin{tabular}{|c|c|}
\hline $\begin{array}{l}\text { Findings from Tin et al. }(2016) \\
{[1,443 \text { workers; mean age } 44.9} \\
(\mathrm{SD}=11.5) ; \text { in } 2014]\end{array}$ & $\begin{array}{l}\text { Findings from Small (2018) } \\
\text { [approximately 3,400 workers; } \\
\text { in 2017] }\end{array}$ \\
\hline Hypertension: $22.6 \%$ (27.7 \%) & Hypertension: $12.6 \%$ aged $\geq 51$ \\
\hline Overweight: $71.7 \%$ (50.0\%) & $\begin{array}{l}\text { Abnormal blood sugar level: } \\
4.95 \% \text { aged } \geq 51\end{array}$ \\
\hline $\begin{array}{l}\text { High total cholesterol: } 19.4 \% \\
(49.5 \%)\end{array}$ & $\begin{array}{l}\text { Abnormal total cholesterol: } \\
14.4 \% \text { aged } \geq 51\end{array}$ \\
\hline $\begin{array}{l}\text { Low level high-density } \\
\text { lipoprotein: } 41.6 \%\end{array}$ & $\begin{array}{l}\text { About } 25 \% \text { of workers are daily } \\
\text { or social drinker }\end{array}$ \\
\hline $\begin{array}{l}\text { High non-fasting blood glucose: } \\
4.3 \%(8.4 \%)\end{array}$ & $\begin{array}{l}\text { Findings from Rowlinson et al. } \\
(2014)[1,628 \text { workers; mean } \\
\text { age } 44.5(\mathrm{SD}=11.68) \text {; in } 2013]\end{array}$ \\
\hline $\begin{array}{l}\text { High-risk smoking: } 48.7 \% \\
(14.8 \%)\end{array}$ & $\begin{array}{l}\text { Long working hours ( } 9 \text { and more } \\
\text { hours per day, six-day per week): } \\
80.9 \%\end{array}$ \\
\hline High-risk drinking: $30 \%(9.6 \%)$ & Work-interference with family \\
\hline $\begin{array}{l}\text { High-risk from low exercise: } \\
87.4 \%(13.0 \%)\end{array}$ & \\
\hline
\end{tabular}


and for abnormal total cholesterol, the percentage was $40 \%$. Taken together, the 3 studies indicate that the construction workforce is sustaining compromised physical health that might lead to significant social and economic consequences (Tin et al., 2016). In this workforce, workers 50 years of age or order sustain an acutely impaired health conditions.

\subsection{Integrated health and safety protection and promotion for construction workforce}

We have learnt of construction workers' (ill)health conditions from preceding paragraphs. The studies suggest that workplace exposures, in particular under the environment of construction site operations, may cause work-related illnesses and diseases. This may lead to impaired working capacity - a situation which older workers is particularly susceptible. In addition, research has indicated that personal characteristics, environmental, and sociocultural (including institutional arrangements) factors have led to work-related illnesses and diseases. These relationships are however far from straightforward although literature suggests that the relationships are rooted in what World Health Organisation terms "work-related conditions" which include the physical and psychosocial aspects of work and the workplace, individual factors (age, gender, personal habits e.g. smoking), and the broader occupational, social, economic, and institutional contexts (Hoonakker and van Duivenbooden, 2010). Because improving the health status, workability, limitations, and barriers in employment arrangements of older workers is important for the workplace health and safety and critical for (older) workers, their families, employers, and the industry at large, there is a need to investigate potential interventions that can be implemented to mitigate the risks associated with ageing workforce. The development of a more holistic approach to improve (older) worker health protection and promotion is needed. In this approach, two factors worker's personal health and personal safety - are combined to increase the impact on worker's overall health and productivity. The underlying rationale is that when health protection and promotion are integrated and deployed in a systemic manner, the workforce would become healthier and safer. Hymel et al. (2011:p.695) has described workplace health protection and promotion as "the strategic and systematic integration of distinct environmental, health, and safety policies and programmes into a continuum of activities that enhances the overall health and well-being of the workforce and prevents work-related injuries and illnesses." The approach involves essential elements that prioritise a hazard-reduced work environment and recognises the role of job-related factors that affect workers' health and well-being (Sorensen et al., 2018). There is an emphasis on the importance of improvements in working conditions that assess and address stressors in the workplace. The approach encompasses workforce participation, job demands, control, worker support, relationships, roles, and organisational change (Cousins et al., 2004).

Sorensen et al. (2016) have proposed a conceptual model for the integration of workplace health protection and promotion. The model is shown in Fig. 1. The model specifies the causal pathways upstream phenomena influence downstream worker safety and health and is built on the premise that improvements in safety and health outcomes can only be achieved through addressing multiple pathways in an integrated manner. "Conditions of work" is placed in the centre of the model as factors determining the safety and health outcomes of workers and as mediators affecting the safety and health behaviours of the workers. But at the same time, conditions of work are also affected by upstream organisational and workers characteristics, and organisational policies, programmes, and practices. In addition, although not shown in Fig. 1, the model operates within the context of labour market, economic, legal, and political forces and social norms and influences. It is in this systemic manner that the concept contributes to the organisational and individual outcomes. The model highlights the complex interplay of individual workers and their immediate work environment which are collectively embedded in the larger context that affects the outcomes of the workers (e.g., health and safety behaviours) and where improvements are likely to be made (Sorensen et al., 2016).

\section{The small scale survey on older workers care 2.1 Method}

The third author of the paper had conducted a small scale survey in December 2017 to investigate the situations on the care of older workers in Hong Kong construction industry. The survey was conducted within a client-based

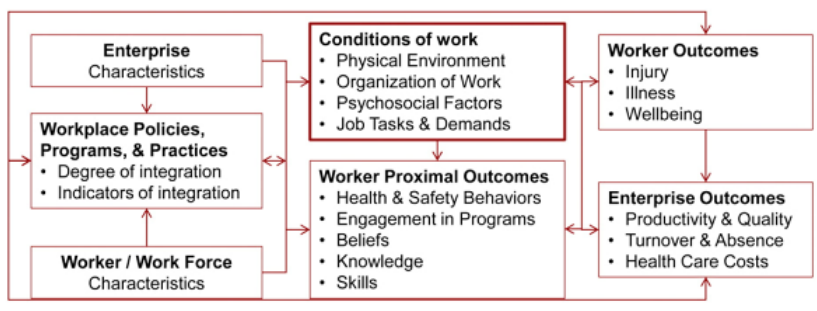

Fig. 1 Sorensen et al.'s (2016) integrated model of workplace health protection and promotion 
benchmarking group in Hong Kong and aimed to explore the arrangements that had been (or had not been) put in place for the care of older workers in the industry. Thirtynine main contractors and two client organisations participated in the survey. The survey investigated the extent of measures implemented by these organisations for the care of older construction workers. These measures include the implementation of (a) specific written policy for the care of older workers, (b) age definition of older worker, (c) health check arrangements, (d) specific site arrangements for elderly workers, and (e) promotional activities. In addition, our participation in a range of activities in construction industry also informs us on the health protection and promotion measures implemented by contractors in Hong Kong. These activities include our participation in a client benchmarking group, industry seminars and events, and the conduct of research projects.

\subsection{Findings}

The 39 main contractors were classified as large-size contractor in Hong Kong. These contractors are capable of handling contract values that exceed HK\$300 million (Euro1:HK\$8.8 as at January 2020). Middle to senior personnel of these organisations responded to the survey including project director, project manager, site agent, project engineer, general manager, etc. The findings of the survey are presented in Fig. 2. In Fig. 2, the sequence of the charts corresponds to the measures being investigated in the survey and the number in the chart represents the number of respondents (i.e. organisations) that implement the measures being asked.

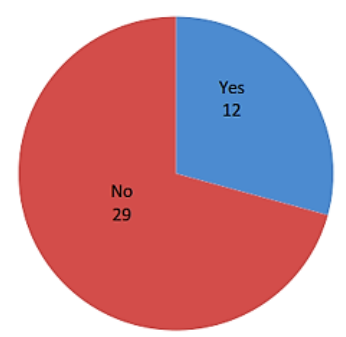

(a) Policy for older workers

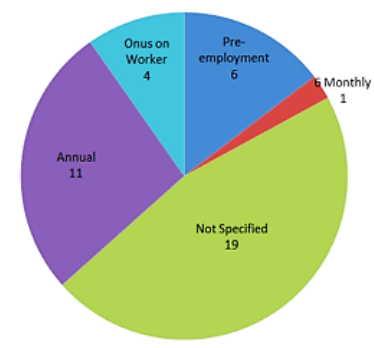

(c) Health check arrangements

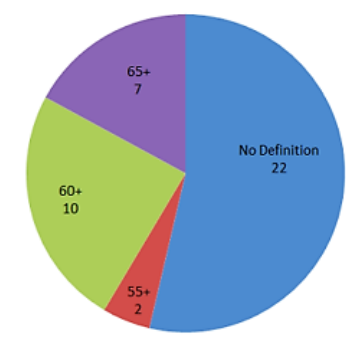

(b) Age definition of older workers

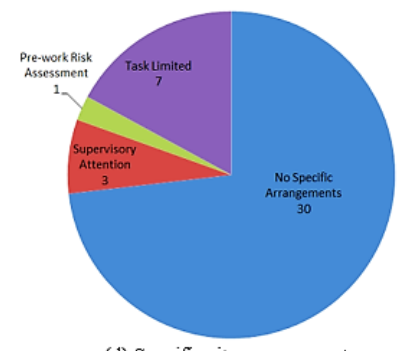

(d) Specific site arrangements
Fig. 2 Findings of the survey on older workers care
In Fig. 2, as shown in chart (a), 29 respondents (71 \%) indicated that no specific written policy was put in place for the care of older workers whereas 12 respondents ( $29 \%$ ) had determined specific age defining arrangements. This observation has led to the finding in chart (b) whereby the overall majority of respondents indicated that there was no age categorisation for older workers and a ten year variation is noted with other organisations who indeed define "older workers" with the age ranges from "55 and above" to "65 and above". For health check arrangements, as presented in chart (c), there is a wide variation on arrangements being adopted. Of particular note is 1 contractor who provides six-monthly hypertension and blood pressure tests for those over sixty years of age. At the other end of the "care" scale 4 respondents placed responsibility on older workers to provide proof of fitness to work on sites. And finally in chart (d) where greatest consistency is shown in that, in most cases, no specific arrangements apply at site related to the care of older workers. Majority of those surveyed (30 organisations, $73 \%$ ) responded in this way.

As for question (e), a range of health-related promotional activities were reported in the survey. Several respondents 9 organisations - placed importance on educational briefing related to healthy lifestyle issues (e.g., diet modification); 3 respondents placed importance on blood pressure / vascular screening and had measures in place to escalate "care" if negative results were noted; 1 respondent was in the process of setting up a specific site medical centre; 1 respondent mentioned of the duty of the site nurse to look out for the welfare of older workers; and 1 respondent mentioned morning exercise as a control related to older workers.

In addition to the survey, anecdotal evidence from our observation of the construction industry in Hong Kong reveals that a myriad of health measures have been implemented by several more progressive contractors. These measures range from basic regular health checks, personalised health advice, lifestyle review, medical counselling; to the integrated health diagnostics, centralised health record, analyses, and company-wide health and work design (Small, 2018). Although these health measures are put in place for the benefits of workers of all ages, older workers may benefit more as they are the group with higher proportion of the workforce that sustains impaired health conditions than their younger counterparts.

\section{Discussion}

The findings point to a general situation of under-appreciation of the ageing workforce in the Hong Kong 
construction industry. This general lack of appreciation and understanding are manifested in the findings that majority of the main contractors have not specified the age limit for workers to be considered "older" and consequently have not implemented specific work practices and site arrangements for this group of workforce. For a few contractors that specified the age limit (ranging from 55- to 65-year-old) and those that have put in place some arrangements - additional supervisory attention, pre-work risk assessment in relation to workers' capacity, and agebased task limitation - there appears to be a need to re-examine the attitudes and assumptions of contractors with regard to the suitability of the older workers for construction operations. In terms of attitude, traditionally, contractors are concerned with additional financial cost in implementing specific work and organisational arrangements to cater for the older workforce and this is within the broader context of construction workforce employment arrangement, client responsibilities, and workers' pay structures (Leaviss et al., 2008) and that, contractors will be unable to recoup the financial outlay in a competitive industry (Drake et al., 2017). Here, economic factors are important barrier to the implementation of age related measures for older workers (Tonnon et al., 2017).

In addition to the economic consideration, the way construction workforce is organised may also contribute to the problem. A majority of constuction workforce is employed under sub-contractors. This workforce can be characterised with frequent and episodic change of employment among those sub-contractors and constuction projects. This pattern of employment often prevent the workforce (including older workers) from receiving effecttive medical care and preventive programmes that are only offered by large main contractors (Ringen and Seegal, 1995). Due to the competitive nature of sub-contracting, sub-copntractors' focus on winning project is based on price and productivity of their workforce. The focus is seldom the workforce's welfare let alone their health conditions. From the main contractor's perspective, this "not my workers syndrome" coupled with the main contractor's indifferent attitude have led to a lack of attention on the ageing workforce.

However, along with this seemingly backward attitude, at play is also a situation of the understanding of works that is based on a set of uninformed assumptions, the assumption that older workers are associated with reduced productivity and that, they are more susceptible to health and safety problems. Despite this attitude, employers are still expected to ensure that workers are physically able to perform their works in safe and effective manner. In this respect, it is possible for employers to implement interventions that minimise biological and physical ageing by matching the task to the capability of workers. For construction operations, assigning physically demanding tasks to capable younger workers (Silverstein, 2008) would benefit a group of workers as the capacity of the older workers to tolerate peak loads decreases with age. Along this arrangement, it is also possible to introduce flexibility to modulate work intensity by encouraging work group self-regulation (Kenny et al., 2016). And as usual, the introduction of ergonomically friendly work environment can reduce the risk of injury in older workers (Loeppke et al., 2013). It is hence possible to maintain older workers' capacity or even get more out of the workforce by modifying existing practices and work conditions without incurring huge financial outlay.

In fact, the focus of construction firms should be to modify the work environment to reduce physical demands, providing alternative work arrangements, and facilitate improvements in workers physical capacity (Jamnik et al., 2013; Kenny et al., 2016). These notions essentially call for a combined health and work conditions intervention. Our industry observations of a few progressive contractors in Hong Kong has revealed of the implementation of an integrated health protection and promotion model as shown in Fig. 3.

A few strategies are used in association with the model. First, the measures in the model include improvements of the conditions of work that include working environment (e.g., providing age-friendly power-assisted work tools, the use of industrial exoskeleton) and work arrangements (e.g., additional risk assessments based on role and capability in relation to workers age, additional health surveillance). Second, a worksite level consultation and training on safety and health are implemented for workers and frontline staffs (e.g., personalised health education and counselling, lifestyle review). These activities help create in site management team the awareness in protecting and promoting workers health and safety. Third, for a few large contracting firms that are endowed with financial resources, telephone health helpline and online health information are made available for the company's authorised users. In addition, as workers age, chronic diseases and functional impairment limit the ability for them to work. Mental health problems (e.g., depression and anxiety) have also been reported as common causes of work disability (Dong et al., 2011). In the model shown in Fig. 3, this conditions are catered for in stress management and 


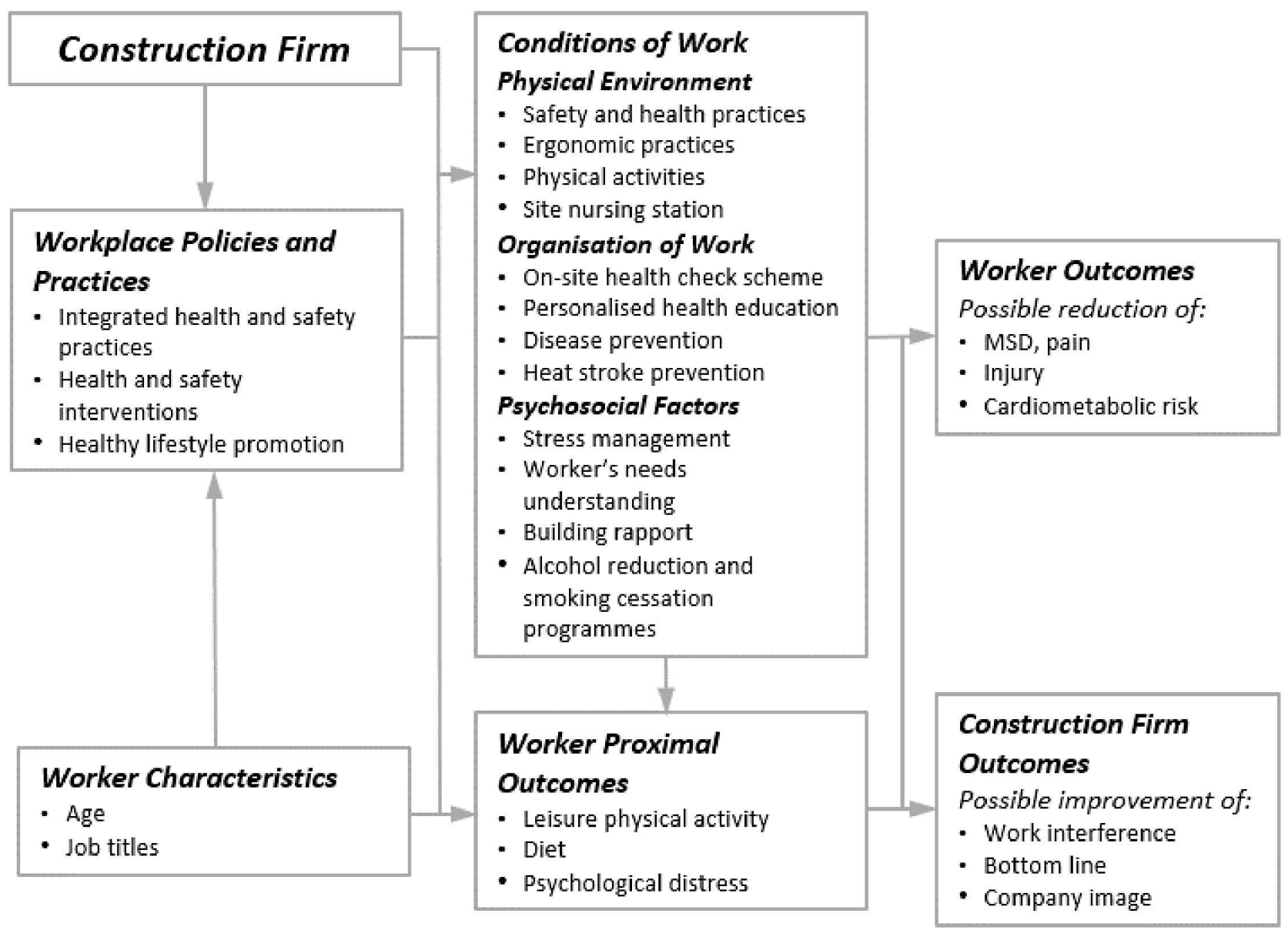

Fig. 3 The application of integrated model of workplace health protection and promotion in construction firms [adapted from Small (2018) and Sorensen et al. (2016)]

workers' needs understanding. As shown in the model, the combination of the measures essentially introduces a preventive approach that is not only beneficial for workers of all ages but is potentially effective in mitigating the risks associated with ageing workforce in construction.

The model in Fig. 3 shows that company policies influence worker health and safety outcome through a few pathways. These influences are mainly mediated through the "Conditions of Work". Company's policies directly affect physical work environment through for example safety and health practices. These practices impact physical demands on older workers in relation to biomechanical sources of strain (Sorensen et al., 2016). The work environment may also support healthy behaviours among workers for example through exercise (see "Leisure physical activity" under Worker Proximal Outcomes). Organisation of work, with the listed activities, will influence worker health and safety outcomes. For example, the implementation of heat stroke prevention measures is likely to reduce the workforce heat stress/stroke incidents. Psychosocial factors deal with job strain, psychological demands, social support, and peer influence. In this regard, initiatives of workplace stress management and rapport building that support health and safety behaviours are likely to lead to improved health behavours (Choi et al., 2010). In addition, positive workplace psychosocial conditions also reduce the risk of Musculoskeletal Disorder (MSD) (Bongers et al., 2002). Essentially, the model and its component measures propagate of a transformational change in the organisation toward a culture of workplace safety and health that are supportive of workers total well-being.

\section{Conclusion}

In this paper, we set out to explore the care measures for older workers and potential interventions implemented by some progressive contractors in Hong Kong. Given the economic pressures of keeping older workers in the construction working population and the need to understand the role of age in the development of disease and the impact on occupational injury and safety, our exploration has shed 
some lights on the attitude of the contracting community in treating older construction workforce which at best can be described as lukewarm (and at worst ignorantly minimalist and shortsighted). But at the same time, our industry observation of a few progressive contractors has revealed of a range of interventions that are in line with the emerging concept of worker health (and safety) protection and promotion - an integrated scheme for workplace safety, health, and well-being - that can potentially bring about positive change in the industry. As shown in Fig. 3, the implementation of such an integrated scheme can help companies to understand the relationships between working conditions and workers safety and health outcomes.

\section{References}

Bongers, P. M., Kremer, A. M., ter Laak, J. (2002) "Are psychosocial factors, risk factors for symptoms and signs of shoulder, elbow, or hand/wrist?: A review of the epidemiological literature", American Journal of Industrial Medicine, 41(5), pp. 315-342.

https://doi.org/10.1002/ajim.10050

Chan, A. P. C. (2018) "Health Profiling of Construction Workers in Hong Kong - 1st and 2nd Phases Study", Presented at The Construction Safety Benchmarking Group (CSBG) meeting, Hong Kong, April, $11,2018$.

Chan, C., Ching, R. (2017) "Announcement of key findings of the $2^{\text {nd }}$ Population Health Survey", [pdf] Centre for Health Protection, Department of Health, Hong Kong, Available at: https:/gia.info. gov.hk/general/201711/27/P2017112700581_272855_1_1511779135 272.pdf [Accessed: 25 January 2018]

Cheng, S. T., Lum, T., Lam, L. C. W., Fung, H. H. (2013) "Hong Kong: Embracing a Fast Ageing Society with Limited Welfare", The Gerontologist, 53(4), pp. 527-533. https://doi.org/10.1093/geront/gnt017

Choi, B., Schnall, P. L., Yang, H., Dobson, M., Landsbergis, P., Israel, L., Karasek, R., Baker, D. (2010) "Psychosocial Working Conditions and Active Leisure-Time Physical Activity in Middle-aged US Workers", International Journal of Occupational Medicine and Environmental Health, 23(3), pp. 239-253. https://doi.org/10.2478/v10001-010-0029-0

Construction Industry Council (CIC) (2016) "Forecast of Manpower Situation of Skilled Construction Workers" [pdf] Construction Industry Council, Hong Kong, Available at: http://www. cic.hk/Forecast_SkilledWorkers_e/20161216_Forecast_ SkilledWorkers e.pdf [Accessed: 16 March 2018]

Construction Industry Council (CIC) (2019) "Data Analysis on Registered Workers, For the period 1/9/2017 to 31/8/2018 (12 Months)", [pdf] Construction Industry Council, Hong Kong, Available at: http:// www.cic.hk/files/page/193/15th\%20Survey\%20Result\%20-\%20 Spreadsheet\%20201808_eng.pdf [Accessed: 25 March 2019]

Cousins, R., MacKay, C. J., Clarke, S, D., Kelly, C., Kelly, P. J., McCaig, R. H. (2004) "Management Standards' work-related stress in the UK: practical development", Work \& Stress: An International Journal of Work, Health \& Organisations, 18(2), pp. 113-136. https://doi.org/10.1080/02678370410001734322
This in turn informs the company on priority setting and more importantly, identify the impact of health and safety on business related outcome. The implementation of such an integrated scheme of workplace health and safety protection and promotion appears to hold promise in the management of ageing workforce. The implementation of such good practices, if done correctly and consistently across the construction industry, will bring the industry forward in terms of its management practices and its reputation. Such good practices will help to ensure that our workplaces are able to meet the senior workers' needs and capacities.

Dong, X. S., Wang, X., Daw, C., Ringen, K. (2011) "Chronic Diseases and Functional Limitations Among Older Construction Workers in the United States: A 10-year Follow-up Study", Journal of Occupational and Environmental Medicine, 53(4), pp. 372-380. https://doi.org/10.1097/JOM.0b013e3182122286

Drake, C., Haslam, R., Haslam, C. (2017) "Facilitators and barriers to the protection and promotion of the health and safety of older workers", Policy and Practice in Health and Safety, 15(1), pp. 4-18. https://doi.org/10.1080/14773996.2017.1289453

Hoonakker, P., van Duivenbooden, C. (2010) "Monitoring working conditions and health of older workers in Dutch construction industry", American Journal of Industrial Medicine: Incorporating Environmental and Occupational Health, 53(6), pp. 641-653. https://doi.org/10.1002/ajim.20838

Hymel, P. A., Loeppke, R. R., Baase, C. M., Burton, W. N., Hartenbaum, N. P., Hudson, T. W., McLellan, R. K., Mueller, K. L., Roberts, M. A., Yarborough, C. M., Konicki, D. L., Larson, P. W. (2011) "Workplace Health Protection and Promotion: A New Pathway for a Healthier - and Safer - Workforce", Journal of Occupational and Environmental Medicine, 53(6), pp. 695-702. https://doi.org/10.1097/JOM.0b013e31822005d0

Jamnik, V., Gumienak, R., Gledhill, N. (2013) "Developing legally defensible physiological employment standards for prominent physically demanding public safety occupations: a Canadian perspective", European Journal of Applied Physiology, 113(10), pp. 2447-2457. https://doi.org/10.1007/s00421-013-2603-1

Kenny, G. P., Groeller, H., McGinn, R., Flouris, A. D. (2016) "Age, human performance, and physical employment standards", Applied Physiology, Nutrition, and Metabolism, 41(6), pp. S92-S107. https://doi.org/10.1139/apnm-2015-0483

Koh, T. Y., Rowlinson, S., Pollock, S. (2019) "Dealing with Ageing Workforce in the Hong Kong Construction Industry: an Initial Exploration", In: Creative Construction Conference 2019, CCC 2019, Budapest, Hungary, pp. 665-671. https://doi.org/10.3311/CCC2019-091

Leaviss, J. A., Gibb, A., Bust, P. (2008) "Understanding the Older Worker in Construction", [pdf] Research Executive Summary of SPARC (Strategic Promotion of Ageing Research Capacity) project, UK, Available at: http://www.sparc.ac.uk/media/downloads/executivesummaries/exec_summary_gibb.pdf [Accessed: 03 February 2018] 
Loeppke, R., Schill, A., Chosewood, L., Grosch, J., Allweiss, P., Burton, W., Barnes-Farrell, J., Goetzel, R., Heinen, L. A., Hudson, T., Hymel, P., Merchant, J., Edington, D., Konicki, D., Larson, P. (2013) "Advancing Workplace Health Protection and Promotion for an Ageing Workforce", Journal of Occupational and Environmental Medicine, 55(5), pp. 500-506. https://doi.org/10.1097/JOM.0b013e31829613a4

López, M. A. C., González Alcántara, O. J., Fontaneda, I., Mañanes, M. (2018) "The Risk Factor of Age in Construction Accidents: Important at Present and Fundamental in the Future", BioMed Research International, 2018, Article ID: 2451313. https://doi.org/10.1155/2018/2451313

Ringen, K, Seegal, J., England, A. (1995) "Safety and Health in the Construction Industry", Annual Review of Public Health, 16, pp. $165-188$.

https://doi.org/10.1146/annurev.pu.16.050195.001121

Rowlinson, S., Koh, T. Y., Shen, Y. Z., O’Shea, D., Howarth, S. (2014) "Worker Health and Wellbeing Month, 2013. Final report to the MTRC and QBE Insurance", Department of Real Estate and Construction, The University of Hong Kong, Hong Kong.

Schwatka, N. V., Butler, L. M., Rosecrance, J. R. (2012) "An Ageing Workforce and Injury in the Construction Industry", Epidemiologic Reviews, 34(1), pp. 156-167.

https://doi.org/10.1093/epirev/mxr020

Silverstein, M. (2008) "Meeting the challenges of an ageing workforce", American Journal of Industrial Medicine, 51(4), pp. 269-280. https://doi.org/10.1002/ajim.20569

Sito, P. (2014) "Skilled workers in short in short supply in Hong Kong's construction industry", South China Morning Post, [online] 18 March 2014. Available at: https://www.scmp.com/property/ hong-kong-china/article/1451437/skilled-workers-short-supply-construction-industry [Accessed: 25 March 2019]

Small, T. (2018) "Empowering Health at Workplace: Our Way to a Healthy and Caring Workplace", Presented at The Construction Safety Benchmarking Group (CSBG) meeting, Hong Kong, January, 23, 2018.
Sorensen, G., McLellan, D. L., Sabbath, E. L., Dennerlein, J. T., Nagler, E. M., Hurtado, D. A., Pronk, N. P., Wagner, G. R. (2016) "Integrating worksite health protection and health promotion: A conceptual model for intervention and research", Preventive Medicine, 91, pp. $188-196$.

https://doi.org/10.1016/j.ypmed.2016.08.005

Sorensen, G., Sparer, E., Williams, J., Gundersen, D., Boden, L., Dennerlein, J., Hashimoto, D., Katz, J., McLellan, D., Okechukwu, C., Pronk, N., Revette, A., Wagner, G. (2018) "Measuring Best Practices for Workplace Safety, Health, and Well-Being: The Workplace Integrated Safety and Health Assessment", Journal of Occupational and Environmental Medicine, 60(5), pp. 430-439. https://doi.org/10.1097/JOM.0000000000001286

Tin, S. P. P., Lam, W. W. T., Yoon, S., Zhang, N., Xia, N., Zhang, W., Ma, K., Fielding, R. (2016) "Workplace Health Promotion: Assessing the Cardiopulmonary Risks of the Construction Workforce in Hong Kong", PLOS One, 11(1), Article ID: e0146286. https://doi.org/10.1371/journal.pone.0146286

Tonnon, S. C., van der Veen, R., Westerman, M. J., et al. (2017) "The Employer Perspective on Sustainable Employability in the Construction Industry", Journal of Occupational and Environmental Medicine, 59(1), pp. 85-91. https://doi.org/10.1097/JOM.0000000000000913

Varianou-Mikellidou, C., Boustras, G., Dimopoulos, C., Wybo, J. L., Guldenmund, F. W., Nicolaidou, O., Anyfantis, I. (2019) "Occupational health and safety management in the context of an ageing workforce", Safety Science, 116, pp. 231-244. https://doi.org/10.1016/j.ssci.2019.03.009

Yi, W., Chan, A. (2016) "Health Profile of Construction Workers in Hong Kong", International Journal of Environmental Research and Public Health, 13(12), Article ID: 1232. https://doi.org/10.3390/ijerph13121232 